\title{
Henry James, Honoré de Balzac
}

\section{Marco Stupazzoni}

\section{(2) OpenEdition}

\section{Journals}

\section{Edizione digitale}

URL: http://journals.openedition.org/studifrancesi/504

DOI: 10.4000/studifrancesi.504

ISSN: 2427-5856

\section{Editore}

Rosenberg \& Sellier

\section{Edizione cartacea}

Data di pubblicazione: 1 aprile 2015

Paginazione: 164

ISSN: 0039-2944

\section{Notizia bibliografica digitale}

Marco Stupazzoni, « Henry James, Honoré de Balzac », Studi Francesi [Online], 175 (LIX | I) | 2015, online dal 01 avril 2015, consultato il 18 septembre 2020. URL : http://journals.openedition.org/ studifrancesi/504; DOI : https://doi.org/10.4000/studifrancesi.504

Questo documento è stato generato automaticamente il 18 settembre 2020.

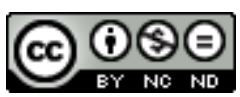

Studi Francesi è distribuita con Licenza Creative Commons Attribuzione - Non commerciale - Non opere derivate 4.0 Internazionale. 


\title{
Henry James, Honoré de Balzac
}

\author{
Marco Stupazzoni
}

\section{NOTIZIA}

HENRY JAMES, Honoré de Balzac, in L'Arte del romanzo. Saggi sulla scrittura e ritratti di autori, introduzione di Agostino LoMBARDo, Milano, Pgreco Edizioni, 2013, pp. 61-95.

1 Questo saggio di Henry James (tratto da Notes on Novelists with Some Other Notes, 1894, 1914) rappresenta probabilmente uno fra i tributi più alti che uno scrittore (e un critico) potesse offrire al suo maestro, l'atto di omaggio più sincero, più leale, più intensamente personale che un romanziere si sentisse intimamente in dovere di rivolgere al proprio «benefattore» e al proprio «padre». Balzac - «Benedettino del presente» (p. 66), «Gulliver fra i pigmei» (p. 65) - si stacca in modo rilevante da ogni altro scrittore, e non solo della sua epoca. Tra tutti i romanzieri, egli «è il più serio» (ibid.) non perché mancasse del senso del comico, ma in quanto volle realizzare, dall'inizio alla fine della suo percorso letterario, "tutto ciò che poteva essere fatto», vale a dire «leggere l'universo, nel modo più aspro e più forte possibile, dentro la Francia del suo tempo, con occhi che consideravano la sua opera sia come il dramma dell'uomo che come uno specchio della massa dei fenomeni sociali» (p. 66). Lo schema e lo scopo costituirono, dunque, per lui, la cosa suprema: Balzac - che vedeva il suo soggetto con ineguagliata intensità di visione fantastica, ma, allo stesso tempo, con la passione quasi maniacale per l'esattezza dei dettagli e per l'infinità delle loro possibili combinazioni ricomponendole alla luce della storia e della scienza - visse e scrisse «in questo perpetuo conflitto e finale impossibilità» (p. 68). L'artista della Comédie humaine è «quasi soffocato dallo storico»: in Balzac, l'ambizione di rappresentare il "grande tutto" si accompagna con la «molteplice ossessione del reale» (p. 74), con gli impulsi dell'ardente e instancabile ricercatore, con l'«infinita estensione, in lui, del pittore e del poeta» (p. 71). Egli visse nella sua commedia umana, in un mondo che, immerso negli aromi del passato, si è rivelato la sua "gabbia»: Balzac «fu condannato dalla sua stessa costituzione, dal suo inveterato vedere "questa cosa che deve essere fatta" come parte integrante, come vera e propria essenza della sua intrapresa» (p. 84). La sua fantasia era 
tutta la sua esperienza: le sue allucinazioni fantastiche si sono concretizzate soltanto nell'idea e nella forma dell'insieme compiendo in tal modo «il miracolo di risolversi totalmente in una molteplice conoscenza» (p. 88). 